\title{
Health Accessibility and Vulnerability among Marginalized Communities: A Study in Urban Slums in Kerala
}

\author{
M. M. Rajeev \\ Assistant Professor, Department of Social Work, School of Social Sciences, \\ Central University of Rajasthan Bandar Sindri, Kishangarh, Ajmer, Rajasthan, India \\ E-Mail: rajeevmm@curaj.ac.in
}

\begin{abstract}
The living environments and its direct impact on health and related areas are much significant in the socioeconomic and environment studies. The vulnerability of the any marginalized sections of the societies needs to be studied and refereed for a change. As far as concerned, the slums are considerably disadvantaged to inadequate health, contaminated water sources, poor sanitation, unhygienic environment and poor quality of living. The census 2011 defines a slum as "residential areas where dwellings are unfit for human habitation" because they are dilapidated, cramped, poorly ventilated, unclean, or "any combination of these factors which are detrimental to the safety and health" (Census, Govt of India, 2011). Roughly 1.37 crore households, or $\mathbf{1 7 . 4 \%}$ of urban Indian households lived in a slum in 2011, data released by the registrar general and census commissioner's office showed. The new data is difficult to compare with previous years, because the 2011 Census covers all 4,041 statutory towns in India, as compared to 2001 when only statutory towns with population over 20,000 were covered. The 2001 data had set India's slum population at $15 \%$ of the total population. The objectives of the study are (1) to understand the major health issues existing in the urban slum (2) to understand the involvement of government and other stakeholders in addressing the multiple issues in the slums (3) to find out the major preventive strategies for addressing the various health issues in the urban slums (4) to highlight possible suggestions to improve the health conditions of the people living in the slums. The methodology employed in the study is analytical, based on a combination of qualitative and quantitative data generated through purposive sampling techniques as well as through focus groups discussions and interactions with stakeholders. A descriptive design was adopted for the study. The universe of the study consists of the two slums in Kollam Corporation. The researcher used random sampling method for selecting the samples and the researcher elicited primary data through questionnaire and for secondary data books, magazines and internet facilities were used. The total sample size is 120 respondents from 2 slums in Kollam district. The collected data from the respondents were tabulated and interpreted and later analyzed. The findings highlighted the slum dwellers need to make aware of the need for improvement in living conditions, and they must readily involve themselves with every phase of the rehabilitation. Practical and innovative approaches need to be put into practice to integrate slums within the cities. Governments need to pay more attention to slums and make concerted attempts to address this problem proactively. Keywords -Vulnerability, marginalized sections, Census 2011, descriptive design
\end{abstract}

\section{INTRODUCTION}

According to UN-HABITAT, around 33\% of the urban population in the developing world in 2012, or about 863 million people, lived in slums. The proportion of urban population living in slums was highest in Sub-Saharan Africa(61.7\%), followed by South Asia (35\%), Southeast Asia (31\%), EastAsia (28.2\%), WestAsia (24.6\%), Oceania (24.1\%), Latin America and the Caribbean (23.5\%), and North Africa (13.3\%). Among individual countries, the proportion of urban residents living in slum areas in 2009 was highest in the Central African Republic (95.9\%). Between 1990 and 2010 the percentage of people living in slums dropped, even as the total urban population increased. The world's largest slum city is in Mexico City.Across the globe around there is a steady increase in people residing in urban area, about one third of these urban dwellers, which amount to nearly one billion people, majority of them live in urban slums, informal settings or sidewalk tents. In addition to rapid population growth, India is also witnessing an explosive growth in the population residing in the urban areas. It is estimated that of the nearly $30 \%$ of India's population or about 300 million people live in towns and cities. Mathematical modeling reveals that this population may up to reach 534 million by 2026. In India in line with rest of the world, more rapid growth of population residing in slums is also witnessed. Nearly one-third of India's urban population or nearly 100 million live in slums which are characterized by overcrowding, poor hygiene and sanitation and the absence of proper civic services. Health systems in India is more focused towards the rural areas having an organizational structure right from grass root to tertiary care and are managed by dedicated staff. However there is a huge deficiency of any such health care structure in the urban areas. To add to this a very rapid growth of urban population has overburdened existing health care system. Majority of health care in urban area is served by the private sector but it's costing, distance and many other factors make private sector facilities out of reach of most urban poor residents(KanthariaSl, 2010).

The inseparable truth is that the health is most important factor of an individual's life.We can understand that the various health issues like nutritional problems, communicable disease, child mortality, women's ill health are needs to be addressed drastically and efficiently to the 
promote health for all as WHO highlighted the slogan in the year of 2000, Health for All.The slums in especially in India have common features in terms of health vulnerability and consequences. In Kerala many slum dwellers facing heavily in health and related issues. The study (Gangadharan K, 2005)urban and slum area very low social class households were educationally backward, their knowledge, level of diseases, available health services. The urbans slums in Kerala having visible issues such has diseases, poor medical care, poor water supply, and basic sanitation, family planning, mother child health, prevention and control of endemic diseases, wastedisposal and social and economic concerns. The people living in the slums in Kerala are known the ill effects of their health but unable to find out a solution due to numerous reasons. This study is an attempt to capture the real health issues of the people living in the urban slums in the targeted areas of the Kollam district of Kerala and also put forward some preventive steps to reduce the health problems with possible policy recommendations.

\section{REVIEW OF LITERATURE}

It is indeed to understand the various contributing factors which lead to the origin of slums in the country. The slums form and grow in many different parts of the world for many different reasons. Major causative elements are including rapid rural-to-urban migration, economic stagnation and depression, high unemployment, poverty, informal economy, poor planning, politics, natural disasters and social conflicts. Strategies tried to reduce and transform slums in different countries, with varying degrees of success, include a combination of slum removal, slum relocation, slum upgrading, urban planning with city wide infrastructure development, and public housing It has been long since a number of non-government organizations are working for the welfare of poor communities living in urban areas. But as it is very difficult to define and categorize who and which community is poor, so is difficult to assert which community is a slum. Adequate and quality data and information about status of poor, their whereabouts, their existing sources of water, their willingnessto pay for water, etc. are very essential to develop pro-poor water supply policy. Since it will only be like beating the bush to do something on for the slum community without scientifically defining them, the NGO Forum for Urban Water and Sanitation has tried to come to a more acceptable definition of slum through a "brainstorming" workshop. The given definition here is based on the workshop, held on 9th November 2004, and further studies that followed it.Defining an area as a slum area is very complex task since there is no any exact definition or documentation exists in the country for defining slum. Organization like LUMANTI has developed its own criteria for slum for Nepal and UN Habitat has its own criteria for defining slum. LUMANTI for Nepal and definition of slum by UN Habitat are worthy to share. Definition of slum by Lumanti;-Slum communities are defined by poverty, low income, inadequate living conditions and sub-standard facilities(SumanThapa 2011). These communities are usually inhabited by socially disadvantaged people (peopleregarded as lower caste). Unlike squatter settlements, the residents of these slum areas generally own their land and houses, which are very small in size and have formal title papers (Lalpurja) to prove their ownership. These communities are also officially recognized by authorities.On the other hand, a slum area, where the residents do not have Lalpurjas is defined as a squatter settlement. Thus, all squatter settlements are slums but a slummay not be a squatter settlement.

Characteristics of slums: Recognizing the various characteristics of the slums plays an important task, a slum is a cluster of houses, a slum is an area therefore, an individual house is not considered as a slum.Slum areas are generally found in periphery of old inner city, which is a marginalized area from the pointof view of old settlements and these days,which is being occupied by new migrants. Lack of access to public services - a slumgenerally lacks access to public servicessuch as sewerage, water supply, roads;street lamps etc. or even if they have them, provide poor service facilities. Then slum is overcrowded area - a slum generally hashigh density of people within the dwellingunit on the basis of space occupancy.Small houses or huts with narrow and darkstreet lanes characterize slums in most ofthe cases (SumanThapa 2011). The residents of the slum belong to low income or economicallydeprived group such as poor tenants. Insome areas, they can also be the people,displaced by disasters or conflict. The residents of the slum may also belong to socially deprived group such as "lower castes". Poorhousing facility is maincharacteristic of slum and the houses in the slum area generally used lowcost building construction materials with poor hygiene and sanitation.Other significant features of theslumsare density of population, difficulties in accessibility to public services such as road, water supply, lack of facility in waste disposals, socio- economic constraints such as prevalence of caste system, issues in the land ownership status, health and sanitation issues etc. Urban slums are settlements, neighborhoods, or city regions that cannot provide the basic living conditions necessary for its inhabitants, or slum dwellers, to live in a safe and healthy environment. The United Nations Human Settlements Programme(UNHABITAT 2012). defines a slum settlement as a household that cannot provide one of the following basic living characteristics: The inaccessibility to one, or more, of the above basic living conditions results in a "slum lifestyle" modeled by several characteristics.

Slums- Crucial Issues: Some of the critical issues and concerns of the people living in the slums needs to be emphasized for a better understanding of the slums. Dense and overcrowded living quarters creates a breeding ground for transmittable diseases, which can lead to the rise of an epidemic. Slum dwellers that do not have access to clean and affordable drinking water are at risk of waterborne diseases and malnutrition, especially amongst children. Health problems occur due to many factors such as urbanization, the ill-health conditions of the 
livingenvironment, inadequate access and use of public health care services, hidden/unlisted slums andrapid mobility.The other key problems associated with health are fertility, maternalhealth, childsurvival, family planning, environmental conditions, infectious diseases and poor access to health care. Poor housing units are vulnerable to natural disaster and destruction because affordable building materials cannot withstand earthquakes, landslides, excessive wind, or heavy rainstorms. Slum dwellers are at greater risk to disaster because of their vulnerability to 'Mother Nature'. Experience says that the slums compounded the severity of the Haiti Earthquake of 2010. Overcrowding and related health issues mainly that rapid growth of urban centers has led to substandard housing on marginal land and overcrowding .Outbreaks of diseases transmitted through respiratory and faeco-oral route due to increased population density. It exacerbates health risks related to insufficient and poor water supply and poor sanitation systems. Lack of privacy leading to mental health issues like depression, anxiety, stress etc.Air pollution can affect the health in many ways with both short-term and long-term effectsShort-term air pollution can aggravate medical conditions like asthma and emphysemaLong-term health effects can include chronic respiratory disease, lung cancer, heart disease, and even damage to other vital organs. Due to increasing urbanization coupled with existing un-sustainability factors and conventional urban water management. Nearly 1.1 billion people worldwide who do not have access to clean drinking water and 2.6 billion people i.e. over 400 million people, lack even a simple improved latrine. Poor slum dwellers commonly suffer from unemployment, illiteracy, drugaddiction, and low mortality rates of both adults and children as a result of not supporting one, or all, of UNHABITAT's basic living conditions.

Formation of slum living in urban setting: If we analyze, it can be seen that in an urban setting, the majority of slum formation is due to rapid urbanization within a developing country. This theory has significance because a population boom, associated with urbanization, creates a greater demand for housing than the urbanized area can offer or supply. This population boom often consists of rural inhabitants who migrate to urban areas where jobs are plentiful and where wages are stabilized. However, the issue is exacerbated by lack of federal and city-government guidance, control, and organization. The inhabitants are mostly rickshaw puller,sex workers, seasonal small vendors, house maid servants with a family income ranging from a meager Rs.1500 to Rs.3000. After a hard and low-earning working day, most of the men spend their daily earnings on homemade illicit liquor. Status of woman's in slum is not respectful; they used to do prostitution to full fill their basic needs to survive. The slum population is constantly increasing: it has doubled in the past two decades. The current population living in slums in the country is more than the population of Britain. Dharavi Slum Mumbai: Mumbai “The Dream city” hold the biggest slum area in India known as Dharavi. Asia's largest slum,
Dharavi, is spread over an area of $1.75 \mathrm{~km}$ along the Mahim river in central Mumbai (Walk Through India 2016). Dharavi is just one of many slum areas in city of Mumbai. Bhalswa Slum Delhi: In"The Heart of India” the Slum population was considered as $20 \%$ of the total population of Delhi, It also has largest child labours. These slums tend to bank of river Yamuna. Slum dwellers from various parts of Delhi have been resettled to Bhalswa. Delhi Government is thinking to launch a survey to prepare a data base of slum dwellers in the city to help them. Delhi has become one of the most unsafe Indian cities for women, due to the large population and crimes. Nochikuppam Slum Chennai: “The city of flyovers" has Nochikuppam slum with 1,300 huts where around 5 thousand people live below poverty level and they don't have enough money for two meals a day.Basanti Slum Kolkata: “The City of Joy” Kolkata has slum area known as Basanti slum, it is one of the major slum areas in Kolkata. One third of Kolkata's population, lived in 2011 registered and 3500 unregistered slums. "The garden city” Bangalore alone holds 570 slums form total of around 2000 slums in State (Walk Through India 2016). It is estimated that about $20 \%$ of Bangalore population reside in slums. The families living in the slum are not ready to move into the temporary shelters, saying it is unjust and risky to live under a flyover. As per the latest comments from people of Bangalore, Rajendranagarslum does not existnow, all the slum dwellers has been rehabilitated. Indirammanagar Hyderabad: "The City of Nizam" around 624689 peoples live in slums area of Hyderabad. There is very little land available for all the people's live in 104 identified and 24 unidentified slums in Hyderabad.Sarojnagarslum Nagpur: "The Orange city" Nagpur has 424 legal slum areas, Sarojnagar is just one of the 424 slums in the city. In Nagpur, approximately $40 \%$ of the population lives in slums. These slums are home to over 1, 42,000 people and cover about 1,600 hectares of prime land. Due to struggle for land in Maharashtra, it was making second largest slum area in Nagpur after Dharavi Mumbai. “The City of Nawabs” Lucknow's population includes large numbers of poor people, many of who live in slums. 20000 persons living in 22 of the 460 slums in Lucknow city (ehbullahpur slum Lucknow). Many people are migrated Lucknow from the different part of the nearest district for daily wages.Satnaminagarslum Bhopal: “The City of Lakes” Bhopal has many slums area, Satnaminagar is one of the oldest slums in Bhopal. Ruhal Nagar and Shanti nagar are first two slums area in Bhopal to be declared opendefecation. Peoples of Bhopal live on streets and these slums provide them shelter and other facility to survive.Approximately 440000 people live in slums (Parivartan slum) within the city of Ahmadabad. Ahmadabad is home to a large population of poor people's living on the river banks. River side slums in Ahmadabad are about 40 yrs. old. Official figure of 46,000 slum dwellers in 47 geographically defined areas- underestimate due to exclusion of many unlisted slums in the state of Gujarat. Slums characterized by poor quality water supply, sanitation, drainage, hazardous physical environment, poor access to public health facilities, overcrowded households, 
insecure livelihoods - health indicators in urban slums often worse than rural areas (D. Kassam 2012).

\section{BACKGROUND AND SCOPE OF THE STUDY}

The study coverstwomajor slums in Kollam district which is under the Corporation of Kollam namely Kacherikulam and Dipopurayidam. The total population of this colony is approximately 90 families and around 500 members are living in this colony. Few years ago, this place was a part of the temple with a pond. Gradually people were stated to build houses and they were settled in this place. Currently the pond was remained as a place where wastes dumped. The temple is protected by the people residing in this place. The government were given them assurance to build houses and few steps were carried out as surveys but no other steps didn't taken in to further. The peoples don't have ownership right for their property. As a resource, an Anganwady under ICDS project is functioning in the place but thereis no health facilities available like PHC'in this colony.The scope of thestudy is to understand the various health and related problems dominant in the slums and also to find out the various ways to prevent the existing problems in the area. Furthermore, the similar study can be replicated in another place having such kind of issues. The study will be helpful for the administration or policy makers to relook in their current policy and can be support to provide support services to the needy people in the present and also in the future. Ultimately, the study can highlight the major issues of the one of the most vulnerable sections of the society in to a public forum which can influence to get maximum support to the slum dwellers for their betterment of life.

\section{OBJECTIVES OF THE STUDY}

1. To understand the major health issues existing in the urban slum.

2. Understanding involvement of government and other stakeholders in addressing the multiple issues in the slums.

3. To find out the major preventive strategies for addressing the various health issues in the urban slums.

4. To highlight possible suggestions to improve the health conditions of the people living in the slums.

\section{MATERIALS AND METHODS}

The methodology employed in the study is analytical, based on a combination of qualitative and quantitative data generated through purposive sampling techniques as well as through Focus Groups Discussions and interactions with stakeholders. A descriptive design was adopted for the study. The universe of the study consists of the two slums in KollamCorporation. The researcher usedrandom sampling method for the selection of the study samples. The researcher elicited primary data through questionnaire and for secondary data books, magazines and internet facilitieswere used. The total sample size is 120 respondents from 2 slums in Kollam district. The collected data from the respondents were tabulated and interpreted and later analyzed.

\section{DATA ANALYSIS AND FINDINGS}

This section isdescribed the data analysis and interpretation of the collected data with the support of statistical methods. First, the researcher presented the details of the sociodemographic information's of the respondents, secondly, general health status of the respondents were analyzed, thirdly, the role of the multiple stakeholders in the study is analyzed, the Prevention programmes for the communicable diseases in the slum are described, the effect of the diseases, close observations and other important findings were mentioned in this paper.

\section{A. Socio-Demographic Data Analysis}

Regarding the age and gender of the respondents the data shows that $33.3 \%$ of the respondents are $40-50$ age groups $30 \%$ of the respondents are $30-40$ age groups, $13.3 \%$ are $50-$ 60 and $20-30$ are 13.3 age groups. Respectively $10 \%$ are 60 70 age groups. This reveals that majority of the respondents are 40-50 age groups. On the gender based calculations made in the study shows that majorities of the respondents are females $81 \%$ than male respondents (19\%) Thus this reveals that majority of the respondents are females. The above table shows that 200 are the minimum wage of the respondent.5000 is the maximum wage of the respondent. This reveals that the respondents are economically backward. In the context of religion wise distribution of the respondents $15 \%$ of people them are Muslim and $85 \%$ respondents are Hindu and 1\% of respondents in Christian. It highlights that the majority of respondents are belonging to Hindu religion. The study shows that $1^{\text {st }}$ standard is the minimum education of the respondents and $12^{\text {th }}$ is the maximum education of the respondents. This reveals that the respondents are educationally backward. Compare to the State's educational status this score is very less and it looks some serious concerns are required to improve the educational status of the people who are living in slums and other locations.

\section{B. The General Health Status of the Respondents}

The health conditions of the study population was made and analyzed in the following diagram which clearly shows the level of satisfaction obtained by the respondents towards their health conditions.

\section{General Health Status of the Respondents (D-1)}

This diagram (D1) shows that $21.7 \%$ of the respondent's satisfaction towards their health is satisfactory. But $25 \%$ of the respondents reported that their general health is not satisfied.13.3\% respondents are highly satisfied and majority of the respondents $40 \%$ are average by the satisfaction of health. This reveals that majority of the respondents are comes under the category of average health. 
This signs there is larger improvement is required to improve the health conditions of the people living in the slums.

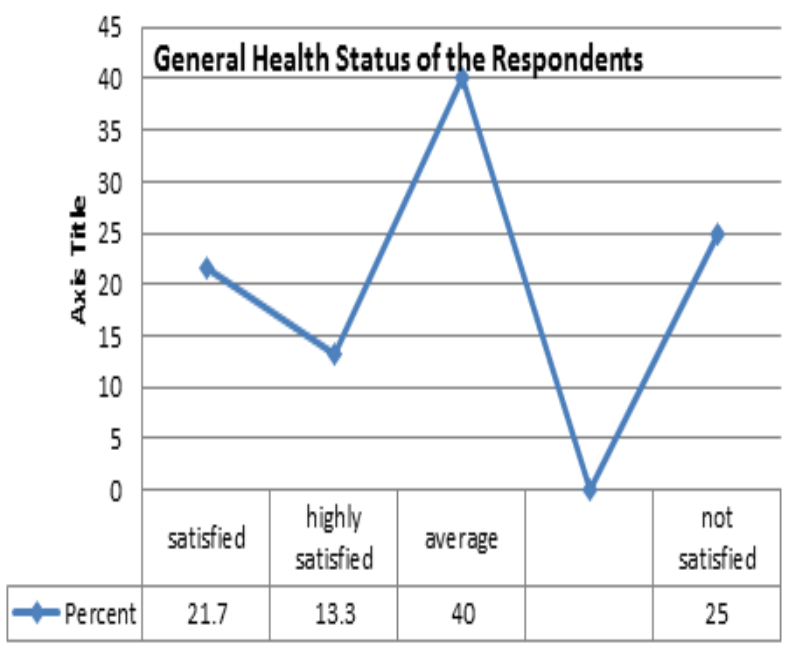

Fig. 1 General Health status of the Respondents

\section{Stakeholders Roles}

One of the important objectives of this paper is to understand the involvement of government and other stakeholders in addressing health and related issues in the slums. The various stakeholders such as PHC's, ASHA workers,Health care Nurses, Civil Society Organizations like SAHAYI trust, Medias, Social Workers and Volunteers are involved in health promotion activities in the slum. This studyreveals that the majorityof the respondents were reported that (48\%) PHCs services are come under average. $20 \%$ of the respondents opined that PHC services are satisfactory, $18.3 \%$ respondents are highly satisfied and only $8 \%$ respondents are not satisfied. The PHCs services includes providing nutritional food to the children, conducing sensitization programmes such as classes on family planning, communicable diseasesetc. This reveals that majority of the respondents are expressed PHCs services are average so there is a vital need to provide better health care services to the people living in the slums for satisfying their medical needs and health protection.The study also collected the services of ASHA Workers in the purview of health care services. Thestudy findings reported that $40 \%$ respondents expressed satisfactionof availability of ASHA workers. $21.7 \%$ are highly satisfied, $21.7 \%$ respondents are responded that average services provided by ASHAworkers.16.7\% respondents are not satisfied of service. Majority of respondents revealed that ASHAworker services satisfactory. This shows that the exiting services are good and better quality of the services are needs to be framed with the support of the people living in the slums and also get ensure the cooperation from the authorities.

Other major stakeholders are health nurses who used to visit the houses of the families residing in the respective wards frequently and address the health concerns of the residents. This study shows that the majority of the respondents $(60 \%)$ opined that, the health nurses visits the home of the respondents frequently, $40 \%$ of the respondents said that the health nurse do not visit the houses. So the response shows that the services of the health nurses in the ward are useful and countable. Providing medicine for the Pregnant Women's, 66.7\% of the respondents are reported that they are getting medicines and rest of the respondents, $33.3 \%$ are different of opinion. These shows the services are needs to be extended to the entire community members for addressing their timely requirements.

\section{E. Communicable Diseases Prevention Programmes in the Slums}

The study reveals that $15 \%$ of respondents expressed high satisfaction about the communicable disease prevention programs carried out by health centers in the study area. $6.7 \%$ of respondent'sshows satisfactory level, about $40 \%$ respondents expressed an averagelevel of satisfaction and $38.3 \%$ are revealed that there are not satisfied. So there is important to increase the awareness of the people in the targeted areas on various health programmes of the government and to provide necessary support to them. In related to the health awareness programmes, the study is revealed $63.3 \%$ of the respondents responded an average satisfaction for the awareness program, 18.3\% respondents satisfied of the health based awareness programs given by PHC. only.16.7\% of them not satisfied towards the program and only $1.7 \%$ of them are reported high satisfaction. This shows that the health awareness programmes needs to be conducted with the participation of the delivery of preventive measures is at most significant activity in related to the health care. The study findings show that $65 \%$ respondents opined that they are not getting preventive medicines during the health emergency. Only 35\% respondents expressed that the distribution of preventive medicines for the needy persons are implemented by the health authorities.This is clearly indicates the possibility of spreading communicable diseases is very high in the targeted places.

\section{F. Diseases Effects}

Other most significant findings are the assessment of the existence of diseases in the targeted area. Thedata shows that $6.67 \%$ TB patients are found in this area and $3.33 \%$ of cancer patients, $11.67 \%$ life style diseases and $78.33 \%$ of the respondents were affected other minor health issues such as respiratory, skin, allergic issues and other general health diseases. The data says that $8.3 \%$ of respondents are satisfied the garbage facility.58.3 are responded not useful for the garbage facility in this areas.33.3\%are responded do not satisfied that the garbage facility. The study says that the majority of the respondents were opined that the garbage facility is not useful and generally the health and hygiene conditions are very poor.The enumerated data shows that $8.3 \%$ of respondentswere satisfied about the health promotion activities of the Corporation. 3.3\%are highly 
satisfied,8.3\% are expressed an average level of satisfaction and the majority of the respondents (80) \% are expressed not satisfaction.

This data shows that $20 \%$ the respondents are benefited classes on the precaution of various diseases. $80 \%$ of respondents did get not the classes on prevention of diseases. The classes given by experts through government programmes like ICDS, Kudumbasree are helped to raise awareness on health issues among people, but still majority of respondentswere notsensitized about prevention for communicable diseases due to their ill participation and other similar factors. Thedata shows that $26.7 \%$ of respondents are satisfied the approaches of the district hospital, 3.3\% are highly satisfied,51.3\%are average of approaching district hospital.18.3\% are reported not satisfaction. The majority of respondentsare eager to approach the hospital for meeting their health needs. Others are also needs to be encouraged to seek medical treatment from the government hospitals so they can afford the cost of the treatment as well as they can increase their awareness on health related problems and solutions.

\section{G. Close Observations}

The other important findings are derived from this study through close observation and with the support of the interaction had with the ley informants of the slum such as senior members of the families, ICDS staff, and health care workers. The people of this place are giving importance to children's education. They are sending children's to school and most of them are study in English medium school. The total strength of Anganwadi students are 7. Due to the emergence of English medium schools, it badly affects the functioning of the Anganwady. They all are sending their children's to LKG at the age of three and four. They all are keen in giving better education to their children because the parents never get those facilities in their childhood. Anganwady is providing lot of services. They are giving ragi packets to the children's from the age of 14-18. Morning snacks are giving to the children's of 6 months to 3years. They are also conducting awareness programs for adolescent girls. They are also providing nutritional food for feeding mothers. Epidemics are the major problems facing by the peoples of this colony. ICDS doesn't have rent own building. Now it is in rented buildings. Most of them are educated in this area. Some of them were completed Post graduate degree but unable to find out a job. The main occupations of the inmates of the colonies are taking wastes and some of them are domestic workers.

The youngsters were using alcohol and tobacco consumption and this will be an important social concern prevailing in the colony. The colony people are using pipe water for drinking and every day they have to wait for water in the morning and evening. They are only four pipes in this area. Some of them have pipe facility in their home. Some houses are built by palm leaves. They don't have well in this place. The water in the pond is not useful because all the wastes from everyone's houses are coming in to this pond. They are not getting support from NGOs. The ICDS teacher is visiting all houses twice in a month. They are getting medicines for epidemics from PHC. So they have to go to private hospital for treatment. At the time of monsoon season, the level of water in the pond is increasing simultaneously, the wastes is also increasing. They are getting lot of awareness classes about clean less. Each person has cooperation between each other's. The SHG activities are more or less limited in this colony so the opportunities for the civic, social and economic participation of the women is very less.

The families are fully depending nearby shops for satisfying their food and other articles. They cannot cultivate anything in this land due to the limitation of space and lack of basic amenities. The uncleaned environment invites lot of mosquitoes and it is affected their life badly. Another notable social concern is observed in this colony is the late marriage of the girls. They only reason for this is that these girls are belonging to this colony and no body from the outside is ready to marry these girls. There are two Kudumpasree units are functioning in this colony with insufficient savings. They are not getting any kind of support from the government.

\section{SUGGESTIONS AND CONCLUSION}

On the basis of the findings of the study, the researcher made certain suggestions. Majority of the respondents stated that PHC services are needs to be improved with sufficient facilities and activities.It should focus much on addressing the health vulnerabilities of the women and children. The slum people are financially backward and the level of education is less so thePHC have to promote more sensitization activities among the mother, children and youth.

The lack of awareness on family planning among people is observed and this should be tackled by giving proper guidance and education classes.Addressing the issues such as communicable diseases, waste management, hygiene and sanitation, and related issues needs to be studied and alternatives and remedies should be done in an emergency mode to satisfy the needs to the people who are living in most difficult conditions. Policy level changes are required to ensure minimum support and facilities to the people who live in the slums.

Health is the wealth of the nation. Not only to the nation, but also to the individual in the nation. So it is very necessary for all individual to give good care to their health. When we analyze the Indian situation where slum people are high in number the main source of their health care delivery is through the Primary Health Centers or district hospital in urban areas. They provide the first hand health care delivery to the slum people. In the present research, the researcher is trying to find out the major health issues of the people living in this area and also find out the mechanisms 
to prevent the existing issues. But the service will become effective only if they provide in a better way. Only then slum people can become average healthy after analyzing the result the researcher found that some of the services like awareness on family planning, visiting mother and child after delivery, etc. are not at all functioning well in the community if they give importance to these functions, then their services will become not effective. Waste is the major problem this area is to affected the people health. The study finding that the not proper waste dumping place in this area. But the government and corporation not supported and focusing them. Local government should develop strategies to prevent the formation of new slums. These should include access to affordable land, reasonably priced materials, employment opportunities and basic infrastructures. The study may help the the government to know the present level and also to make further modifications in their activities then only they can attain, "HEALTH FOR ALL” within few decades.

\section{REFERENCES}

[1] Census. (2011). Government of India, Office of the Registrar General \& Census Commissioner, India.

[2] Kantharia Sl. (2010). Urban Health Issues in India- Need of the Day, National Journal of Community Medicine, 1(1), 1-2.

[3] Gangadharan K. (2005). Utilization of Health Services in Urban Kerala: A Socio Economic Study Serials publications, New Delhi.ISBN-81-86771-92-1, 12-16.,

[4] SumanThapa . (2011). An Assignment on Case study about Slum in Nepal, case study, 4-6.

[5] UN-HABITAT. (2012). Annual report series, 978-92-1-132555-3, 23-25.

[6] Web.http://www.unhabitat.org/pmss/listItemDetails.aspx?publication $\mathrm{ID}=2917$

[7] Walk Through India. (2015). List of Top Indian Cities Living in Slums, 2-4.

[8] D Kassam. (2012). Health Vulnerabilities in Urban Slum Areas of Bhuj, Gujarat for KMVS Bhuj, Gujarat. Bhuj Information Center, Socio-Economic Studies, Bhuj Bole Chhe, 5-7. 